\title{
Mining 4.0 - the Impact of New Technology from a Work Place Perspective
}

\author{
Joel Lööw ${ }^{1} \cdot$ Lena Abrahamsson ${ }^{1} \cdot$ Jan Johansson $^{1}$ (DD \\ Received: 6 May 2019 / Accepted: 28 June 2019 / Published online: 15 July 2019 \\ (C) The Author(s) 2019
}

\begin{abstract}
Industry 4.0 offers new possibilities to combine increased productivity with stimulating workplaces in a good work environment. Used correctly, digitalization can create attractive jobs in safe control room environments, which provide space for the employee's full expertise and creativity. This is true also for the mining industry. But, to succeed, it is important to analyze the development from a worker's perspective. What will happen to their work? What skills will be needed in the mine of tomorrow? We must also consider the risks, such as privacy issues, increased stress, and work-life boundaries. These questions must be understood if we are to create workplaces that can attract a young and diverse workforce to tomorrow's mining industry. In this article, we try to illustrate what the new technology can mean for the individual miners. We formulate the notion of Mining 4.0 (Industry 4.0 in the mining industry), where we try to create an image of how the future might look from a miner's perspective and how mining companies may navigate their way to a future that works for all miners. To illustrate the range of possible outcomes, we formulate two scenarios: one utopian and one dystopic. At the end of our article, we bring forward six recommendations that can be considered a beginning of a road map for the human side of Mining 4.0.
\end{abstract}

Keywords Industry $4.0 \cdot$ Mining $4.0 \cdot$ Attractive jobs $\cdot$ Safety $\cdot$ Utopia $\cdot$ Dystopia

\section{Introduction}

Future mining will be shaped in a context where it is necessary to produce at costs that are determined by international competition [1]. The mining industry has overcome many challenges with the help of technology [2], but technology alone will not be enough in the future. So, while having a technical production process that is at the forefront is one the most important conditions for the future, having a competent workforce that can handle the technology is another but equally important condition - here, generational issues are a big challenge to overcome. Digitalization is a recurring buzzword that is often claimed to be able to combine these two requirements. But how do we build such a production system?

The emerging digitalization in the mining industry offers new possibilities for increased productivity and at the same time could create stimulating workplaces in a good work environment. Inspiration often comes from the positive images

Jan Johansson

jan.johansson@ltu.se

1 Human Work Science, Luleå University of Technology, 97187 Luleå, Sweden of the German industrial concept, Industrie 4.0. Used correctly, digitalization can indeed create attractive jobs in safe control room environments, which provide space for the employee's full expertise and creativity: the control room receives online processed information from the "rock", from personnel, and from machinery, and control room equipment makes it possible to control and fine tune the complete operation, from resource characterization to the final product. Sensors and the extensive use of cameras and image techniques even permit "live performances" in the control room [2].

But, in many countries, there is a lack of skilled personnel-both miners and mining engineers. The present workforce is aging and companies have difficulties recruiting young talented people that in general are not very interested in working in the mining industry [3-5]. To be able to handle these problems wisely, it is important to analyze the development from a worker's perspective. What will happen to their work? What skills will be needed in the mine of tomorrow? We must also consider the risks, such as privacy issues, increased stress and work-life boundaries. Work, no matter how attractive, may not be so attractive if it follows one home. If safety is achieved through constant supervision, this might be too high a price to pay. These questions must be considered if 
we are to create attractive workplaces that can attract young people to tomorrow's mining industry-a workforce that leverage its future high-tech environment.

Thus, in this article, we try to illustrate what the new technology can mean for the individual miners. We will try to create an image of how the future might look from a miner's perspective and how mining companies may navigate their way to a future that works for all miners.

\subsection{Industry 4.0-the Engineering Industry Is Showing the Way}

Industrie 4.0 is a strategy that was shaped by the German government in 2013. Industry 4.0 (to use its English name) is described as the fourth industrial revolution. After the steam engine, electricity, and electronics, the revolution consists of an implementation of "Internet of Things, Humans, and Services" where the entire production process is included in internet-based networks that transform ordinary factories to smart factories. The German concept as a whole is formulated in the report "Recommendations for implementing the strategic initiative Industrie 4.0 - Final report of the Industrie 4.0 Working Group" [6]. Similar concepts have appeared all over the world. The Chinese government promotes a similar idea under the name Made in China 2025 [7] and the Japanese government has launched Society 5.0 [8].

Meanwhile, the German vision paints a bright picture of the future industry in which virtual and physical worlds will be linked into a powerful "whole" through the integration of software - from product development and production, machines will not just do "physical work" but also perform calculations [9, 10]. This is described as cyber-physical systems, or even sociocyber-physical systems: smart ventilation, smart logistics, smart maintenance, smart machines, and other smart systems continuously exchange information with themselves and with human workers. The German strategy highlights the potential for skill expansion and an enriching working life with more challenging work tasks.

Kagerman et al. [6] noted that it is necessary for companies to have a sociotechnical approach where the participation of employees in job design is central. Without participation, the desired effects may not be achieved at all. Several commentators have argued that Industry 4.0 requires a flat organization with more organizational innovations, learning, enhanced human-machine interaction, and a more human-focused view on the new technology [cf. 11-13]. The German strategy also underlines that these developments will reduce the need for employees; functions such as remote controls and preventive maintenance will reduce labor costs but increase the employment security of the remaining factory staff $[6,13]$.

\subsection{Mining 4.0-an Upcoming Concept}

Industry 4.0 will also come to affect the mining industry. In fact, some mines have taken important steps towards the digitalized mine of the future. Gradually, the mining industry gets closer to the visions of Industry 4.0 and fully automated mines as well as more technologically sophisticated ore-processing facilities. Analogous to the application of Industry 4.0 in a mining context, we conceptualize Mining 4.0 as a mining operation where the miner is an expert who ensures that production runs smoothly. A Mining 4.0 operator is not confined to a control room. Instead, real-time process data and the status of machines follow the miner as they move around the mine. The miner solves problems directly at the source by remotely interacting with other operators, experts, suppliers, and customers in multi-competent teams. Production control could even be done in a "digital twin" far away from the factory. In short, Mining 4.0 envisions an augmented miner with senses and memory extended through technology. This technology takes advantage of and supports human skills and increases situational awareness through sensors embedded in the clothes of operator, for example, while keeping an uninterrupted operational vigilance. This could be essential in difficult mine environments, to manage the effects of heat and long shifts.

Romero et al. [14] formed a typology of the future Industry 4.0 operator: Operator 4.0. It built on eight stereotypes that can be seen as the core of the new technology; we have modified them to relate to the future miner:

- The super-strength miner uses biomechanical support for increased limb movement and increased strength and endurance.

- The augmented miner uses augmented reality (AR) for integrating information from the digital to the physical world. Examples include maintainers receiving direct assistance from equipment manufacturers. Through special glasses that send and receive live video, both parties would be able to see the problem - which can then be solved through instructions from the equipment manufacturer.

- The virtual miner uses virtual reality (VR) for simulation and training of risky real-life situations. In fact, VR training is already relatively common in mining [15] and is probably one of the industries where it sees the most application. This includes training for high-risk scenarios, such as fire events and simulating new equipment (how will the new machine look, if it will fit in drifts etc.). In principle, it is possible to place the entire control room and production control in a VR environment and thus make it independent of location.

- The healthy miner uses wearable sensors for monitoring health-related metrics as well as GPS location. These 
developments have also already taken place in the industry, to a certain extent. For example, there are advanced positioning systems in use and there have been projects on the application of sensors for monitoring miner's health [cf. 16].

- The smarter miner uses intelligent personal assistants for interfacing with machines, computers, databases, and other information systems. Currently, there are examples where RFID tag systems are used together with a smartphone app to rapidly and easily report malfunctioning equipment.

- The collaborative miner uses collaborative robots for performing repetitive and strenuous tasks. In mining, there are semi-autonomous machines, such as loaders where the operator first "teaches" the machine a path — which it then follows automatically - while the operator controls it remotely during the actual loading. Here, the repetitive and strenuous task of driving to and from the muck pile is taken over by the machine.

- The social miner uses enterprise social networking services for interaction between operators and between operators and the Internet of Things. The introduction of underground Wi-Fi and 5G has made this possible. While most mines do not have special enterprise social networks, the access to Internet in mines also means an access to social media. Already, there are mines where the implementation of mine-spanning Wi-Fi has meant underground operators use group chats to exchange information.

- The analytical miner uses big data analytics to discover useful information and predict relevant events.

This classification points to a number of technical possibilities; all will affect human labor-some good and some bad. But this development is not about creating new kinds of jobs. Rather, it is a development that means that most current jobs will be influenced by these characteristics and developments. Miners will not disappear, but they will be different in the future. We have chosen to call them Miner 4.0.

\subsection{Miner 4.0-Working Life in a Digital Mine}

Mining 4.0 will not only change the technological landscape of mining workplaces and organizations. It also means a knowledge transformation. Here, skills and knowledge go from bodily and tacit to abstract and theoretical [see 17]. In an optimal scenario, Mining 4.0 develops mining companies into learning organizations that require workplace learning and continuous education. Kern and Schumann [18] put this in terms of a transformation from craftsman-like qualifications into technical qualifications. New demands for team work, responsibility, and comprehensive understanding of production flow can be understood as a movement from process- dependent qualifications to process independent qualifications [cf. 18-22]. What was earlier the tacit knowledge [23] of the worker formalizes into theoretical knowledge, digitalized, and used in computers and smartphones. But in this transition, there is also a negative potential. Early, Bainbridge [24] identified problems in automating new processes. When a manual task is automated, usually, the former manual operators become the operators of the new system. These operators might perform well within the system because, having previously worked with it, they have a fundamental understanding of the technology they control. The next generation of operators might not have this understanding. This also raises the question of how a miner's practical skills can be passed along to the smart mining system programmer. Many machine operators can tell if there is a maintenance problem or feel a more efficient operation method to increase productivity that a programmer does not know. Still, we know that some of these "seat of the pants" methods are counter-productive. Examples include directly emulating the control design of LHDs when designing their remote control. The initial thought was that this would improve productivity, but it was later realized that more specialized controls were required [17].

While workers may experience upskilling that asks of employees more theoretical, comprehensive, and communication tasks, there may also be deskilling characterized by fragmentation of craft knowledge and work tasks [17]. This also implies possible polarization: parts of the workforce are upskilled, while parts are left the same or deskilled. Maybe, we come back to the old debate about "high-tech winners and losers" [25], or even the worker A and B team [18, 26]?

Regardless, the transformation implied in Mining 4.0 has effects on workplace cultures and identities [cf. 27, 28]. Qualifications, identity, and gender will be created and recreated when faced with new technology and a changing context. Several of the work tasks previously performed by teams may come to be performed by solitary workers equipped with different types of equipment for digital assistance. This loss of workmates may feel bitter, but at the same time, new types of multifunctional teams are created, whose main work takes place in centralized control rooms [1, 17]; teamwork does not disappear completely, but takes new forms. Mining work has traditionally been seen as physically demanding, requiring a certain type of worker: a brave and strong man. The new context will require knowledge and skill that is more abstract and theoretical. A common optimistic scenario is that this opens up for women and other previously underrepresented categories to enter and master different types of industrial work, e.g., in mining and process industries. Even if this scenario is realized, it does not ensure an unproblematic implementation process. Existing structures and culture are hard to change - and trying to change them will provoke resistance. Losing one's identity and symbolic aspects of work, such as the view of the miner as a strong and brave man, can be 
painful. These views can lag behind the new technology, new qualification demands and (formal) organizational changes. This conflict, between the view of mining as physical demanding and the technology that turns the work almost into a desk job, can create "restoring forces" [29]. Moreover, the workers' collective [cf. 30,31 ] is built and sustained by identification and on norms of likeness between the workers. New technology that threatens to disrupt this can be controversial.

In the optimistic visions of Mining 4.0, smart systems, automation, and remote control will take over dangerous as well as routine work so that operators can focus on learning, creating, and valuing work tasks in a safe environment [9]. Even if the mining industry will not reach this positive vision, there will be new types of mining work and new types of work environments. Thus, there will also be new types of work environmental problems. For example, with remote control, operators can get the freedom to decide where she or he should work. But freedom might also mean higher demands of availability, perhaps $24 \mathrm{~h}$ a day, 7 days a week, 365 days a year. This may erase boundaries between work and private life. Furthermore, the increased ability to control and monitor the individual might create risk for anxiety and job strain [32].

Mining 4.0 also represents an opportunity to empower people; there are opportunities for wider communication that provides information that builds knowledge and understanding and gives the miners "super powers" [33]. One example is sensors integrated into work clothes that can be connected to a preventive safety system for miners in dangerous environments [34]. When introducing such systems, one must be aware that these systems can be perceived as a threat to personal integrity and must be handled carefully. The technology could be used to control workers rather than the production process [35]. In a safety critical situation, knowledge of positioning and well-being may be welcomed, but the information should not be misused.

In view of this pessimistic perspective, robots and technology could take over not only the dangerous jobs but also all the jobs. This is denied by the system's advocates. They argue that in contrast to previous automation initiatives, the focus within Industry 4.0 is not primarily to replace the human; instead, the human is integrated into Industry 4.0 [36]. But a reduced need for traditional labor can certainly be expected, where low-skilled professions are hit hardest [37]. At the same time, new jobs will be created, primarily in computer technology, IT, and mathematics [38]. With increased complexity, traditional operator work is also expected to shift to more mental work [36]. In the Swedish conception of Industry 4.0, problems of unemployment are discussed. The argument is that employment in the industry will decrease, but on the other hand, prosperity increases. This leads to increased consumption, which means increased growth in the service sector - this can compensate for the loss of industrial jobs [39]. This points towards the fact that some issues cannot be solved by the mining industry alone. To manage the shift to digitalized industry requires that there are social systems in place to reeducate displaced workers. But the mining industry will not stand alone; as the digitalization wave passes through every industry, this need will arise in many other places. Cooperation between industries, and between industry and government, is likely to be required. However, as the mining industry is struggling to recruit people in the first place, a decreased dependence on labor might be a desirable development. Here, competence development is crucial. For the unions, it is an insurance that workers can change work tasks rather than being made redundant. For mining companies, it means the current workforce can be employed in new tasks. Thus, a new workforce does not necessarily need to be recruited.

Another critical perspective is that parts of production control will take place remotely, perhaps from low-wage countries. Workers and contractors can be located all over the world, but can be active in the same physical or virtual workplaces. In combination with new forms of employment, such as crowd sourcing [40], this creates what can be described as liquidized employment [41]. This can lead to an entirely new type of labor relations [42]. In this new global industrial context, it becomes difficult for trade unions to find a basis for negotiations. This can erode the relationships between companies and trade unions and eventually create an unstable labor market with more strikes and conflicts. The German union IG Metall is trying to address the problem by opening itself to self-employed members; in 2015, they promoted the launch of the platform "Fair Crowd Work" [43], intended to gather crowd workers from all over the world and allow them to exchange their views and rate working conditions on on-line labor platforms.

This shows that the effect a (revolutionary) technology change in the mining industry or in individual mining companies will not be limited to the industry or company-it will have significant bearing on society as well. A mine can have a significant economic impact on its surrounding society. If a mine is mostly remote controlled, few benefits may end up in the local community. If the notion of an $A$ and $B$ team is taken to its edge, with the A team being located in cozy offices far from the mine, the local community might be stuck with bearing the costs of injuries and ill-health of the B team. Even if this is not the case, small mining communities may be hard pressed to provide the advanced skills and competencies required by the future mine. This usually means using fly-in/fly-out solutions and contractors. Extensive use of contractors introduces a risk of an "us and them" culture emerging [44], which can make work environment management more difficult. Additionally, some mining companies that have relied extensively on contractors have found that they have lost control over competence; they no longer possess core competencies and, in some cases, are entirely dependent on contractors to provide it for them [2]. This can impair technological development and introduce risks to mine production. Moreover, even future mining activities must secure its social license to operate. In this discussion, companies are expected to construct a strong 
technical and social infrastructure that ensures the survival of a society after the mining has ceased [45]. Extensive FIFO practices decrease opportunities to meet this expectation.

These issues are important to address and keep in mind during the technological development towards Mining 4.0. Otherwise, there is a risk that the new technology will not receive social acceptance. And if technology is not accepted, or indeed if the mine is not accepted, it does not matter how good the technology is; it simply will not be used, or the mine will be allowed to be established.

\subsection{Utopia or Dystopia?}

How will these trends and driving forces affect tomorrow's mining work? There is, of course, no clear answer to that question. There is no inherent technological determinism in the development; it will depend on a number of choices that we make. But that also means that we can shape the mining industry of the future. To illustrate the range of possible outcomes, we formulate two scenarios below, one utopian and one dystopic. Let us start with the dystopia:

You have to be grateful that you even have a job, now that everything is automated. Most of the jobs have disappeared, and the entire municipality is depopulated, without acceptable social service. There is a small colony with cheap labor that the company flies in, mostly cleaning staff, but we rarely meet them. They are not part of the trade union and usually stick to themselves. I am ashamed that company does not take greater responsibility for the community. After all, we are the ones who have built the company's wealth.

There are some qualified jobs located in the control center above ground, but most of these jobs have moved to town and are carried out remotely via the net. Some work is even done from India - they say it's cheaper that way. It's not just an A and B team anymore; we now also have a $\mathrm{C}$ team.

What remains for us is mostly maintenance work, but it is no longer qualified work. Most of it is wearing augmented-reality glasses and carrying out tasks according to the instructions that we get from central maintenance or a machine supplier, far away. Sometimes we have to put on an exo-skeleton if there is heavy lifting. There used to be a few women in our group, but they didn't stick around for long. They said the exo-skeletons would make it easier for them, but they could hardly reach the controls. But then again, we insisted that they be bulky, so that they would look like real mining robot. Now there's also these collaborative robots that are supposed to help us with heavy tasks. But they and every other system require so many cameras and sensors, so the company sees everything we do. You easily get the feeling that Big Brother sees you. As soon as you get a new idea about how something can be done in a better way, it should be added directly to the production computer so that it can be standardized. And it is not worth trying to keep the idea for yourself - the system at once notices if you deviate from the expected.

But everything is not bad. The work is not as dangerous as before, because we do not work at the front nowadays, and there are no diesel vehicles anymore. Underground everything is automated, but of course we must install the electricity and access points, and then you notice that the company has reduced the ventilation. The blasting gases still remain far into the shift and you can feel your heading getting heavier as the day drags on. What I miss most is my workmates; we have our mobile phones and tablets so that we can keep in touch with each other, but it is not the same as when working with the boys.

The utopian vision becomes much more pleasant to accept:

Most of the underground work is automated and no one works near the front anymore. The production control takes place from a bright and pleasant control room above ground, or collaborative visualization rooms as they are called nowadays. The routine monitoring work has been automated; with AI you get a better stability in production - at least until something completely unexpected happens, then our skills are needed. Our professional role has been extended to include the entire value flow, from mountain to customer. Of course, we do not control the flow, but it is a transparent system where we can see how our work contributes to the bigger picture. If we see an opportunity for improvement, we can switch over to our digital twin to experiment and test the outcome; then we have access to a large amount of logged production data that we can dig into ("data mining", they call it). We have a flat organization and I have learned a lot at work through this; programming, production planning, I have even been involved in the development of the new mining machines! It is always fun if you can trim the production; and then not only financial measures apply, but also so-called green measures, such as saving water or reducing greenhouse gas emissions. We are quite proud that our company takes a great social responsibility, not only for the environment but for a prosperous society that can offer a rich social and cultural environment.

When something goes wrong in the production, it is indicated in our mobile phones and usually we can solve it with a few keystrokes. But sometimes we have to go into a VR model and maybe direct a robot to a crusher to break apart a boulder. If the error has not occurred 
before, we sometimes have to go down into the mine to understand what has happened. Then we can bring the entire production control in our mobile tablets so we quickly can restart the production flow. When we are forced to go down into the mine, we always wear a safety vest with sensors so that one can follow where we are and warn if any dangerous environmental factors appears, or if something seems strange to our health. It is a pleasant atmosphere at our workplaces. For many of us who are a little older, it was difficult to learn the new systems, but the company wisely realized the value of our experiences, especially when the new system should be started up. Nowadays, the level of education is high among all employees. We have gained many new valuable impressions because many employees come from other cultures, and the even gender balance has had a positive impact on our well-being. It used to be that there were only men here, but now we're almost 50-50. Last month my daughter even started working for the company. She is a computer science major but works as much with my colleagues as she does with a computer. For a long time, I thought I would be the last miner in the family. It feels good to know that there will be a new generation, and that young people have stopped moving away. It seems the company's investments in the community, and insistence on training and using locals, really payed off.

\section{Conclusions}

While we have exaggerated some of our descriptions above to drive the point home, we do believe both scenarios are probable. Mining 4.0 can definitely represent a positive development, but there are many questions that must be cleared. The development is necessary to keep a competitive mining industry, but it requires reflection and consideration so that more problems are not created than are solved. In this, there will be some critical junctions. Based on our experiences and the discussion we conducted above, we want to bring forward a number of recommendations that can be considered a beginning of a road map for the human side of Mining 4.0:

- First, there is the economic bottom line. A mine must turn a profit if it is to survive. It must thus be able to produce at costs that are determined by international competition. But it cannot do this at the expense of everything else, and the economic bottom line must be weighed against other factors. More ways measuring success may be required, ways that capture, e.g., social factors.

- Mining 4.0 will cause a reduced need for traditional labor. Any reduction in the workforce must be managed with great transparency and in close cooperation with the trade unions. While letting go of redundancies might be beneficial in the short term, this also means letting go of lots of knowledge and experience. Retraining the workforce may be a more favorable option.

- New competencies will be needed. All employees must be included in this competence development; leave nobody behind. As noted, there is probably a lot of potential in the old workforce.

- Create a flat organization based on a sociotechnology that empowers employees and encourages their creativity. To ensure that the new technology works on everyone's terms, the surrounding community may also have to be involved. This might be especially important in securing a license to operate.

- Handle privacy and integrity issues in close cooperation with the trade unions. This data collection can play important roles in safety and organizational learning, but there are also many pitfalls. Most concerns are legitimate and can be used to form more effective technology.

- Embed all changes in a context of great social responsibility. The mine is not limited to the mine. Changes in the mine may very well affect larger parts of society, especially due to the increased interconnectedness that digitalization offers. Conscious management of these issues may be even more important in the future.

It is important that the mining industry is active in creating Mining 4.0, but we also know that it will take time and there will be much traditional work environment work needed before this becomes reality. We must be vigilant and attentive to all aspect of modern mining-future as well as past.

Acknowledgments Open access funding provided by Lulea University of Technology. This article is based on experiences from the EU project SIMS - Sustainable Intelligent Mining Systems (Grant agreement number: 730302).

\section{Compliance with Ethical Standards}

Conflict of Interest The authors declare that they have no conflict of interest.

Open Access This article is distributed under the terms of the Creative Commons Attribution 4.0 International License (http:// creativecommons.org/licenses/by/4.0/), which permits unrestricted use, distribution, and reproduction in any medium, provided you give appropriate credit to the original author(s) and the source, provide a link to the Creative Commons license, and indicate if changes were made.

\section{References}

1. Abrahamsson L, Johansson B, Johansson J (2009) Future of metal mining: sixteen predictions. Int J Min Miner Eng 1:304-312. https:// doi.org/10.1504/IJMME.2009.027259 
2. Lööw J, Johansson B, Andersson E, Johansson J (2018) Designing ergonomic, safe and attractive mining workplaces. CRC Press, New York

3. Hebblewhite B (2008) Education and training for the international mining industry - future challenges and opportunities at: first international future mining conference, 19-21 November, Sydney

4. Darling P (2011) Mining: ancient, modern, and beyond. In: Darling P (ed) SME Mining engineering handbook, vol 1, 3rd edn. SME, Englewood, pp 3-9

5. Oldroy GC (2015) Meeting mineral resources and mine development challenges. Aachen fifth international mining symposia, Mineral Resources and Mine Development, Aachen

6. Kagerman H, Wahlster W, Helbig J (2013) Recommendations for implementing the strategic initiative Industry 4.0. Acatech, München

7. Wübbeke J, Meissner M, Zenglein MJ, Ives J., \& Conrad, B (2016) Made in China 2025: The making of a high-tech superpower and consequences for industrial countries. Mercator Institute for China Studies, 17:2017-09.

8. Government of Japan (2016) The 5th science and technology basic plan. https://www8.cao.go.jp/cstp/english/basic/5thbasicplan.pdf. Accessed 12 July 2019

9. Gill S (2014) Industry prepares for the next industrial revolution. Control Engineering 27th of June 2013. http://www.controleng. com/single-article/industry-prepares-for-the-next-industrialrevolution

10. Lasi H, Fettke PDP, Kemper HG, Feld DIT, Hoffmann DHM (2014) Industry 4.0. Bus Inf Syst Eng 6(4):239-242. https://doi. org/10.1007/s12599-014-0334-4

11. Dombrowski U, Wagner T (2014) Mental strain as field of action in the 4th industrial revolution. Procedia CIRP 17:100-105. https:// doi.org/10.1016/j.procir.2014.01.077

12. Kopacek P (2015) Automation and TECIS. IFAC-Papers-OnLine 48(24):21-27. https://doi.org/10.1016/j.ifacol.2015.12.050

13. Lee J, Kao HA, Yang S (2014) Service innovation and smart analytics for Industry 4.0 and big data environment. Procedia CIRP 16: 3-8. https://doi.org/10.1016/j.procir.2014.02.001

14. Romero D, Stahre J, Wuest T, Noran O, Bernus P, Fast-Berglund Å, Gorecky D (2016) Towards an operator 4.0 typology: a humancentric perspective on the fourth industrial revolution technologies. In Proceedings international conference on computers \& industrial engineering (CIE46).

15. Horberry T, Burgess-Limerick R, Steiner LJ (2011) Human factors for the design, operation, and maintenance of mining equipment. CRC Pres, Boca Raton

16. Bodin U, Grane C, Lööw J (2016) Teknisk rapport BASIE: Bärbara sensorer för ökad personsäkerhet (Technical report BASIE: Wearable sensors for increased safety). Luleå University of Technology, Luleå

17. Abrahamsson L, Johansson J (2006) From grounded skills to sky qualifications: a study of workers creating and recreating qualifications, identity and gender at an underground iron ore mine in Sweden. J Ind Relat 48(5):657-676. https://doi.org/10.1177/ 0022185606070110

18. Kern H, Schumann M (1974) Industriarbeit und arbeiterbewußtsein. Europaische Verlagsanstalt, Frankfurt am Main

19. Kern H, Schumann M (1987) Limits of the division of labour: new production and employment concepts in West German industry. Econ Ind Democr 8(2):151-170. https://doi.org/10.1177/ 0143831 X8782002

20. Bright J (1958) Automation and management. Harvard University, Boston

21. Blauner R (1964) Alienation and freedom: the factory worker and his industry. University of Chicago Press, Chicago

22. Johansson J (1986) Teknisk och organisatorisk gestaltning: exemplet LKAB (technological and organization Gestaltung: the LKAB example). PhD Dissertation, Luleå University of Technology
23. Polanyi M (1967) The tacit dimension. Routledge, London

24. Bainbridge L (1983) Ironies of automation. Automatica 19(6):775779. https://doi.org/10.1016/0005-1098(83)90046-8.

25. Rifkin J (1995) The end of work: the decline of the global labor force and the dawn of the post-market era. Tarcher Putnam, New York

26. Braverman H (1974) Labour and monopoly capital. Monthly Review Press, New York

27. Wenger E (1998) Communities of practice. University Press, Cambridge New York

28. Fenwick T (2005) Learning as grounding and flying: knowledge, skill and transformation in changing work contexts. Paper at the conference From grounded skills to sky qualifications, 17-19 august 2005, Kiruna, Sweden

29. Abrahamsson L (2009) Att återställa ordningen. Boréa Bokförlag, Umeå

30. Lysgaard S (1961) Arbeiderkollektivet. Universitetsforlaget, Oslo

31. Fältholm Y (1998) Work, cooperation and professionalization. PhD-thesis. Luleå University of Technology

32. Hoonakker P, Korunka C (2014) Intoduction. In: Korunka C, Hoonakker P (eds) The impact of ICT on quality of working life. Springer, Dordrecht, pp 1-7

33. Feki MA, Kawsar F, Boussard M, Trappeniers L (2013) The internet of things: the next technological revolution. Computer 46(2): 24-25. https://doi.org/10.1109/MC.2013.63

34. Alam MM, Hamida EB (2014) Surveying wearable human assistive technology for life and safety critical applications. Sensors 14(5):9153-9209. https://doi.org/10.3390/s140509153

35. Roman R, Najera P, Lopez J (2011) Securing the internet of things. Computer 44(9):51-58

36. Gorecky D, Schmitt M, Loskyll M, Zühlke D (2014) Humanmachine-interaction in the industry 4.0 era. Porto Alegre, Brazil, 12th IEEE International Conference on Industrial Informatics

37. Kazancoglu Y, Ozkan-Ozen YD (2018) Analysing Workforce 4.0 in the Fourth Industrial Revolution and proposing a road map from operations management perspective with fuzzy DEMATEL. J Enterp Inf Manag 31(6):891-907

38. Ghobakhloo M (2018) The future of manufacturing industry: a strategic roadmap toward industry 4.0. J Manuf Technol Manag 29(6):910-936

39. Goverment Offices of Sweden (2016) Smart industry - a strategy for new industrialisation for Sweden. Stockholm: Ministry of Enterprise and Innovation. https://www.government.se/498615/ contentassets/3be3b6421c034b038dae 4a 7ad75f2f54/nist statsformat_160420_eng_webb.pdf. Accessed 12 July 2019

40. Howe J (2008) Crowdsourcing. Crown Publishing Group, New York

41. Holtgrewe U (2014) New, new technologies, new technology. Work Employ 29(1):9-24

42. Johansson B, Johansson J, Abrahamsson L (2010) Attractive workplaces in the mine of the future : 26 statements. Int J Min Miner Process Eng 2(3):239-252

43. IG Metall (2016) Frankfurt paper on platform-based work - proposals for platform operators, clients, policy makers, workers, and worker organizations. IG Metall, Frankfurt

44. Nygren M, Jakobsson M, Andersson E, Johansson B (2017) Safety and multi-employer worksites in high-risk industries: an overview. Ind Relat 72(2):223-245. https://doi.org/10.7202/1040399ar

45. Ail KK, Baffi EY (2007) Environmental impact of artisanal and small scale gold mining in developing countries. Paper presented at the sixteenth international symposium on mine planning and equipment selection, December 2007, Bangkok

Publisher's Note Springer Nature remains neutral with regard to jurisdictional claims in published maps and institutional affiliations. 